\title{
Terrestrial solar radiation driven photodecomposition of ciprofloxacin in clinical wastewater applying mesostructured iron(III) oxide
}

\author{
Daniel R. Wagner ${ }^{1} \cdot$ Kevin Ament $^{1} \cdot$ Lina Mayr $^{1} \cdot$ Thomas Martin $^{1} \cdot$ André Bloesser $^{1} \cdot$ Holger Schmalz $^{1}$. \\ Roland Marschall ${ }^{1} \cdot$ Friedrich E. Wagner ${ }^{2} \cdot$ Josef Breu $^{1}$
}

Received: 23 March 2020 / Accepted: 16 September 2020 / Published online: 29 September 2020

(C) The Author(s) 2020

\begin{abstract}
Cationic cylindrical polymer brushes based on polybutadiene-block-poly(2-vinylpyridine) were applied as structure-directing agent for mesostructuring $\mathrm{Fe}_{2} \mathrm{O}_{3}$ nanoparticles into nanotubes. After temperature-controlled template removal, the obtained nonwoven catalysts were tested for the photodegradation of ciprofloxacin under terrestrial solar radiation. At a slightly basic $\mathrm{pH}$ value, as typically encountered in clinical wastewaters, the mesostructured $\mathrm{Fe}_{2} \mathrm{O}_{3}$ shows a 4.5 times faster degradation of ciprofloxacin than commercial Aeroxide ${ }^{\circledR} \mathrm{TiO}_{2} \mathrm{P} 25$. Even wide-bandgap $\mathrm{ZnO}$, mesostructured in the same way, is 1.6 times slower. Moreover, the non-woven-like structure of the catalyst allows for easy recovery of the catalyst and operation in a continuous flow reactor.
\end{abstract}

Keywords Wastewater treatment $\cdot$ Photocatalysis $\cdot$ Ciprofloxacin $\cdot \mathrm{Fe}_{2} \mathrm{O}_{3} \cdot$ Mesostructured $\cdot$ Cylindrical polymer brushes

\section{Introduction}

The removal of pharmaceutical residues like $\beta$-blockers, antihistamines, X-ray contrast media, or antibiotics from clinical wastewater represents a serious challenge because of their microbial toxicity (Bound and Voulvoulis 2005; Pal et al. 2010; Jiang et al. 2013; Loos et al. 2013). In Europe, ciprofloxacin is the most commonly ascribed fluoroquinolone antibiotic. As a broad spectrum antibiotic, active against grampositive and gram-negative bacteria, it is applied against complicated bacterial infections of the urinal tract or skin infections, especially in hospitals (Martins et al. 2008; Van Doorslaer et al. 2011; Costa et al. 2018). For hospitals, a daily

Responsible editor: Sami Rtimi

Electronic supplementary material The online version of this article (https://doi.org/10.1007/s11356-020-10899-6) contains supplementary material, which is available to authorized users.

Josef Breu

josef.breu@uni-bayreuth.de

1 Bavarian Polymer Institute (BPI) and Department of Chemistry, University of Bayreuth, 95440 Bayreuth, Germany

2 Physics-Department E15, Technical University of Munich, James-Franck-Straße, 85748 Garching, Germany water consumption between 400 and $1200 \mathrm{~L}$ per bed is usual (Boillot et al. 2008). These clinical wastewaters contain up to $101 \mu \mathrm{g} \mathrm{L}^{-1}$ ciprofloxacin, and the level steadily increased by $15 \%$ since the 1990s (Hartmann et al. 1998; Lindberg et al. 2004). Toxicity against prokaryotic and eukaryotic organisms hampers standard biological treatment of the wastewater (Brown et al. 2006).

Consequently, clinical wastewaters need pretreatment before entering municipal wastewater treatment plants. One promising approach is the in situ generation of highly reactive radical species via "advanced oxidation processes (AOPs)." In photocatalytic AOPs, these reactive species can be generated by photocatalytic transition metal oxides such as $\mathrm{ZnO}$ or the well-established Aeroxide ${ }^{\circledR} \mathrm{TiO}_{2} \mathrm{P} 25$ from Evonik. Utilizing solar energy as clean energy source to drive AOPs makes photodegradation most attractive (Gaya and Abdullah 2008; Paul et al. 2010; Khan et al. 2015; Guo et al. 2019).

In our previous work, we were able to show that $\mathrm{ZnO}$ nanotubes are superior over Aeroxide ${ }^{\circledR} \mathrm{TiO}_{2} \mathrm{P} 25$ in the photocatalytic degradation of ciprofloxacin (Bojer et al. 2017). Because of the slightly basic $\mathrm{pH}$ found for clinical wastewaters ( $\mathrm{pH} \approx 8)$, adsorption of ciprofloxacin, which at this $\mathrm{pH}$ is an anion (isoelectric point (IEP) at $\mathrm{pH}=7.4$ ) onto the positively charged surface of $\mathrm{ZnO}$ nanotubes (point of zero charge (PZC) at $\mathrm{pH}=8.9$ ), is electrostatically driven. Consequently, 
and contrary to $\mathrm{ZnO}$, the like-charged surface of $\mathrm{TiO}_{2}(\mathrm{PZC}=$ 6.5) hampers an efficient photocatalytic degradation. Unfortunately, the large bandgap of both $\mathrm{TiO}_{2}(3.2 \mathrm{eV}(\mathrm{Wu}$ et al. 2015)) and $\mathrm{ZnO}$ (3.4 eV (Bojer et al. 2017)) allow only for an absorption of the very small UV fraction of the terrestrial solar spectrum. Clearly, photocatalysts adsorbing in the visible region would be advantageous, and therefore, iron oxide photocatalysts attract a steadily growing interest. Their absorption near the maximum of the solar spectrum (bandgap $\alpha-/ \gamma-\mathrm{Fe}_{2} \mathrm{O}_{3} \approx 2.2 \mathrm{eV}$ (Litter and Blesa 1988)), cost-efficiency, abundancy, and non-toxicity makes them promising candidates as photocatalyst in environmental waste management (Khedr et al. 2009; Maji et al. 2012; Wu et al. 2015).

In this work, $\mathrm{Fe}_{2} \mathrm{O}_{3}$ was mesostructured by electrostatic self-assembly of citrate-stabilized $\mathrm{Fe}_{2} \mathrm{O}_{3}$ nanoparticles with cationic cylindrical polymer brushes (CPBs) acting as structure-directing agent (SDA; Fig. 1). After template removal by calcination in air, nanotubes were obtained that are aggregated into non-woven structures, which resemble the structure of the previously published mesostructured $\mathrm{ZnO}$. The mesostructured $\mathrm{Fe}_{2} \mathrm{O}_{3}$ was tested in the photodegradation of ciprofloxacin under irradiation with the terrestrial solar spectrum and compared to commercially available Aeroxide ${ }^{\circledR}$ $\mathrm{TiO}_{2} \mathrm{P} 25$ and mesostructured $\mathrm{ZnO}$.

\section{Materials and methods}

\section{Chemicals}

If not mentioned otherwise, all chemicals were purchased from Sigma-Aldrich, Germany, and used as-received without further purification.

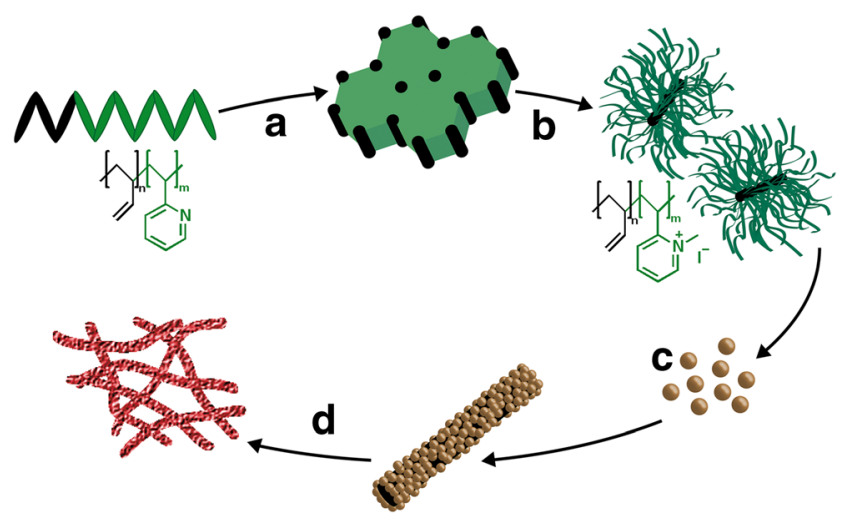

Fig. 1 General scheme for catalyst preparation: hexagonally packed polybutadiene (PB) cylinders embedded in a poly(2-vinylpyridine) (P2VP) matrix resulting from the self-assembly of the diblock copolymer (A). Crosslinking of the PB cylinders and quaternization of the matrix yields water-soluble cationic CPBs (B) which can be used as template that is loaded with $\mathrm{Fe}_{2} \mathrm{O}_{3}$ nanoparticles (C). Calcination transforms the hybrid material into a mesostructured non-woven consisting of pure $\mathrm{Fe}_{2} \mathrm{O}_{3}$ (D)

\section{Synthesis of the diblock copolymer template}

The polybutadiene-block-poly(2-vinylpyridine) (BV) diblock copolymer was synthesized by sequential living anionic polymerization in THF initiated with sec-butyllithium as published (Yelamanchili et al. 2009; Müllner et al. 2012; Bojer et al. 2017). The determination of composition and molecular weight (by a combination of ${ }^{1} \mathrm{H}-\mathrm{NMR}$ spectroscopy (Bruker Ultrashield AC300) and matrix-assisted laser desorption-ionization-time of flight mass spectrometry (MALDI-TOF MS, Bruker Reflex III)) resulted in $\mathrm{B}_{19} \mathrm{~V}_{81}{ }^{60}$. In this notation, the subscripts denote the mass fraction of the corresponding block in wt- $\%$ and the superscript gives the number-average molecular weight in $\mathrm{kg} \mathrm{mol}^{-1}$. The molar mass dispersity of $\bigoplus_{\mathrm{M}}=$ 1.02 was determined by size-exclusion chromatography in THF.

A hexagonally ordered film of typically $1 \mathrm{~g} \mathrm{~B}_{19} \mathrm{~V}_{81}{ }^{60}$ with $0.1 \mathrm{~g}$ photoinitiator (Lucirin-TPO, BASF) was prepared by solvent-casting from chloroform and was subsequently cross-linked using a UV hand lamp (Hoenle, $2 \mathrm{~h}$ per side). Afterward, the film was dispersed in $200 \mathrm{~mL}$ chloroform and the P2VP block was quaternized by dropwise adding of $3 \mathrm{~mL}$ iodomethane (99\%). Once the solvent and iodomethane solution were evaporated, the quaternized product was washed with pentane, dissolved in MilliQ water, and lyophilized.

\section{Synthesis of the iron oxide nanoparticle dispersion}

Iron oxide nanoparticles were synthesized as follows: iron(III) chloride hexahydrate $(21.62 \mathrm{~g}, 80 \mathrm{mmol})$ and iron(II) chloride tetrahydrate $(7.96 \mathrm{~g}, 40 \mathrm{mmol})$ were dissolved in $50 \mathrm{~mL}$ and $16 \mathrm{~mL}$ MilliQ water, respectively. The iron(II) solution was acidified with $2 \mathrm{~mL}$ hydrochloric acid (25\%). Both solutions were mixed under vigorous stirring and added slowly to 650 $\mathrm{mL}$ ammonia solution (15\%). The black dispersion obtained was heated to $60^{\circ} \mathrm{C}$ for $10 \mathrm{~min}$ to evaporate excess of ammonia. After sedimentation with a magnet, the residue was washed several times with MilliQ water until a $\mathrm{pH}$ value of 8 was reached. Nitric acid (2 M, $160 \mathrm{~mL})$ was added for oxidation, and the solution was kept at $80{ }^{\circ} \mathrm{C}$ for $5 \mathrm{~min}$. After addition of iron(III) nitrate nonahydrate solution $\left(160 \mathrm{~mL}, 0.56 \mathrm{M}\right.$, preheated to $80{ }^{\circ} \mathrm{C}$ in order to avoid significant temperature loss), the mixture was stirred for another $25 \mathrm{~min}$ at $80{ }^{\circ} \mathrm{C}$. The reddish brown particles were sedimented with a magnet, and the supernatant liquid was discarded. The residue was redispersed in a small amount of MilliQ water, dialyzed for 7 days against sodium citrate tribasic dihydrate $(0.005 \mathrm{M}$, daily exchange with fresh solution) and centrifuged ( $2 \mathrm{~h}$ at $5000 \mathrm{rpm}$ ). The nanoparticle dispersion was diluted with MilliQ water to a solid content of $7.5 \mathrm{mg} \mathrm{mL}^{-1}$. 


\section{Synthesis of the iron oxide nanotubes}

For the synthesis of the $\mathrm{Fe}_{2} \mathrm{O}_{3}$ hybrid material, $150 \mathrm{mg}$ of quaternized $\mathrm{B}_{19} \mathrm{~V}_{81}{ }^{60}$ was dispersed in $150 \mathrm{~mL}$ deionized water followed by addition of $120 \mathrm{~mL}$ of the citrate-stabilized nanoparticle dispersion $\left(7.5 \mathrm{~g} \mathrm{~L}^{-1}\right)$ and stirring for 1 day. The brownish precipitate was removed from the supernatant liquid by centrifugation ( $3 \mathrm{~min}, 3500 \mathrm{rpm}$ ), washed 5 times with MilliQ water and lyophilized. The organic template was removed in a tube furnace at $500{ }^{\circ} \mathrm{C}$ for $5 \mathrm{~min}\left(180 \mathrm{~K} \mathrm{~h}^{-1}\right.$ heating and cooling rate) under a constant stream of synthetic air (mixture of 21 vol.-\% oxygen and 79 vol.-\% nitrogen). Sintering leads to the formation of an all inorganic nonwoven structure.

\section{Photocatalytic degradation}

The photocatalytic degradation of the anionic antibiotic ciprofloxacin was done in a self-constructed continuous flow reactor (Fig. S1).

The synthesized iron oxide photocatalyst $(20 \mathrm{mg}$ ) was dropcasted on a glass microfiber filter (Whatman, $37 \mathrm{~mm}$ diameter) and $400 \mathrm{~mL}$ ciprofloxacin solution $\left(c=2 \times 10^{-5} \mathrm{~mol} \mathrm{~L}^{-1}\right)$ with a $\mathrm{pH}$ value of 8 (borate/hydrochloric acid buffer) were circulated at a flowrate of $12 \mathrm{~L} \mathrm{~h}^{-1}$. After equilibration, the catalyst was irradiated with the solar spectrum (300-W Xenon arc lamp from LOT Quantum Design, AM1.5 filter, $1000 \mathrm{~W} \mathrm{~m}^{-2}$ ), and the degradation was monitored using UV-Vis spectroscopy (samples were taken every 5-15 min). Baseline-corrected spectra were recorded in the range of 350-200 nm. The area of the most intense band (240-300 $\mathrm{nm}$ ) was used for monitoring the degradation with time (Fig. S2).

\section{Instruments}

The distribution of hydrodynamic diameters of the nanoparticles was analyzed with a Particle Analyzer Litesizer 500 (Anton Paar, Germany) at $20^{\circ} \mathrm{C}$ in automatic mode. For calculating the number-weighted hydrodynamic particle size distribution, the absorption coefficient and refractive index of $\mathrm{Fe}_{2} \mathrm{O}_{3}$ were used (Polyanskiy 2019). Furthermore, the zeta potential was measured at $20{ }^{\circ} \mathrm{C}$ and computed applying the Smoluchowski approximation.

Mössbauer measurements were performed in transmission geometry with a spectrometer operating with a sinusoidal velocity waveform. The source was about $25 \mathrm{mCi}$ of ${ }^{57} \mathrm{Co}$ in $\mathrm{Rh}$. The gamma rays were detected with a proportional counter filled with a $\mathrm{Kr} / \mathrm{CO}_{2}$ mixture. Measurements at liquid He temperature were performed in a liquid $\mathrm{He}$ bath cryostat, in which both the source and the absorber were cooled to $4.2 \mathrm{~K}$. The spectra were fitted with appropriate superpositions of Lorentzian lines grouped into quadrupole doublets or magnetic sextets.
Transmission electron microscopy (TEM) measurements of the nanoparticles were performed with a JEOL JEM2200FS field emission energy filtering transmission electron microscope (FE-EFTEM) operated at an acceleration voltage of $200 \mathrm{kV}$. Zero-loss filtered micrographs $(\Delta \mathrm{E} \sim 0 \mathrm{eV}$ ) were recorded with a bottom-mounted CMOS camera system (OneView, Gatan) and processed with DM 3.3 image processing software (Gatan). Images of the hybrid material were taken on a Zeiss LEO EM992 Omega EFTEM at an acceleration voltage of $200 \mathrm{kV}$. Zero-loss filtered micrographs $(\Delta \mathrm{E} \sim 0$ $\mathrm{eV}$ ) were recorded with a bottom-mounted CCD camera system (Ultrascan 1000, Gatan) and processed with DM $1.9 \mathrm{im}-$ age processing software (Gatan). Samples were prepared by drop-coating dilute dispersions onto carbon-coated copper grids and evaporation of the liquid.

Scanning electron microscopy (SEM) images were acquired with a LEO 1530 FESEM equipped with a field emission cathode. Samples were prepared by drop-coating dilute aqueous dispersions onto silicon wafers.

Nitrogen physisorption data were collected with a Quantachrome Autosorb 1 at $77 \mathrm{~K}$ after degassing the samples at $383 \mathrm{~K}$ for $16 \mathrm{~h}$.

UV-Vis absorption spectra were measured on a Varian Cary 300 using Helma precision cells made of Quartz SUPRASIL (type 100-QS, light path $10 \mathrm{~mm}$ ). Reflectance spectra of the powdered samples were measured using the Diffuse Reflectance Accessory of a Cary 5000 UV-Vis-NIR Spectrophotometer.

Thermogravimetric analysis (TGA) was performed on a Netzsch TG 209F1 Libra under synthetic air. All samples were measured from 25 to $800{ }^{\circ} \mathrm{C}$ at a heating rate of $10 \mathrm{~K}$ $\min ^{-1}$.

Powder X-ray diffraction (PXRD) measurements were done on a STOE Stadi P diffractometer in Debye-Scherrer geometry with monochromatic $\mathrm{Ag} \mathrm{K}_{\alpha 1}$ radiation and a MYTHEN2 4K detector (4 MYTHEN2 R 1K Si-strip detector modules) in moving mode from $2.5^{\circ} 2 \Theta-70^{\circ} 2 \Theta$ (Thomae et al. 2019). Rietveld refinement was done with TOPAS Academic applying a fundamental parameters approach for profile fitting. Implemented macros were used to obtain crystallite sizes. The volume-weighted average crystallite size was obtained assuming spherical particles.

Mott-Schottky plots were measured in $0.1 \mathrm{M} \mathrm{Na}_{2} \mathrm{SO}_{4}$ solution $(\mathrm{pH}=5.3)$ and performed on a Zahner Zennium potentiostat. A three-electrode setup with a working electrode of the obtained iron oxide catalyst, a $\mathrm{Ag} / \mathrm{AgCl}(3 \mathrm{M} \mathrm{NaCl})$ reference electrode, and a $\mathrm{Pt}$ counter electrode was used. Measurements were conducted from -0.4 to $1.2 \mathrm{~V}_{\mathrm{RHE}}$ at $100 \mathrm{~Hz}$.

The PZC was determined using a ParticleMetrix StabiSizer PMX 200C. Thirty milligrams of catalyst in $10 \mathrm{~mL}$ MilliQ water were titrated with $0.01 \mathrm{M} \mathrm{NaOH}$ while monitoring the streaming potential vs. $\mathrm{pH}$ value. 


\section{Results and discussion}

\section{Synthesis of $\mathrm{Fe}_{3} \mathrm{O}_{3}$ nanoparticles}

Particle size distributions of the iron oxide nanoparticles were determined by dynamic light scattering (DLS) and TEM (Fig. 2). DLS gave a mean hydrodynamic particle diameter of $27 \mathrm{~nm}$ corresponding to an average numberweighted diameter of gyration of $12 \mathrm{~nm}$ (hard spheres (Clara-Rahola et al. 2012); number-weighted hydrodynamic diameter of $16 \mathrm{~nm}$ ). Furthermore, no large aggregates or agglomerates were observed. Evaluation of 100 nanoparticles from TEM micrographs yielded a median particle diameter of $9 \mathrm{~nm}$. As expected, TEM gives slightly smaller values than the hydrodynamic diameters determined by DLS.

Phase and purity of the iron oxide nanoparticles were discerned via PXRD and Mössbauer spectroscopy. The PXRD pattern of the nanoparticles (Fig. 3a) showed reflexes of $\gamma-\mathrm{Fe}_{2} \mathrm{O}_{3}$ with broad full width at half maximum as expected for nanoparticles. Rietveld refinement applying TOPAS Academic software (Fig. S3, Table S1) gave average coherently scattering domain sizes of 4.67(3)-6.51(4) nm.

The Mössbauer spectrum recorded at $4.2 \mathrm{~K}$ (Fig. 4a) showed a well-developed sextet from magnetic splitting and can be fitted with two sextet subspectra as typically found in $\gamma-\mathrm{Fe}_{2} \mathrm{O}_{3}$. Isomeric shifts of $\delta=0.05 \mathrm{~mm} \mathrm{~s}^{-1}$ and $\delta=0.29 \mathrm{~mm}$ $\mathrm{s}^{-1}$ with hyperfine fields of $52 \mathrm{~T}$ and very low quadrupole shifts match with $\mathrm{Fe}^{3+}$ atoms in tetrahedral and octahedral sites of $\gamma-\mathrm{Fe}_{2} \mathrm{O}_{3}$, respectively. No impurities of $\mathrm{Fe}_{3} \mathrm{O}_{4}$ were found. The room temperature Mössbauer spectra (Fig. S4) are typical for $\gamma-\mathrm{Fe}_{2} \mathrm{O}_{3}$ nanoparticles that undergo superparamagnetic relaxation in a regime where the relaxation is too fast to yield sextet patterns with narrow lines as

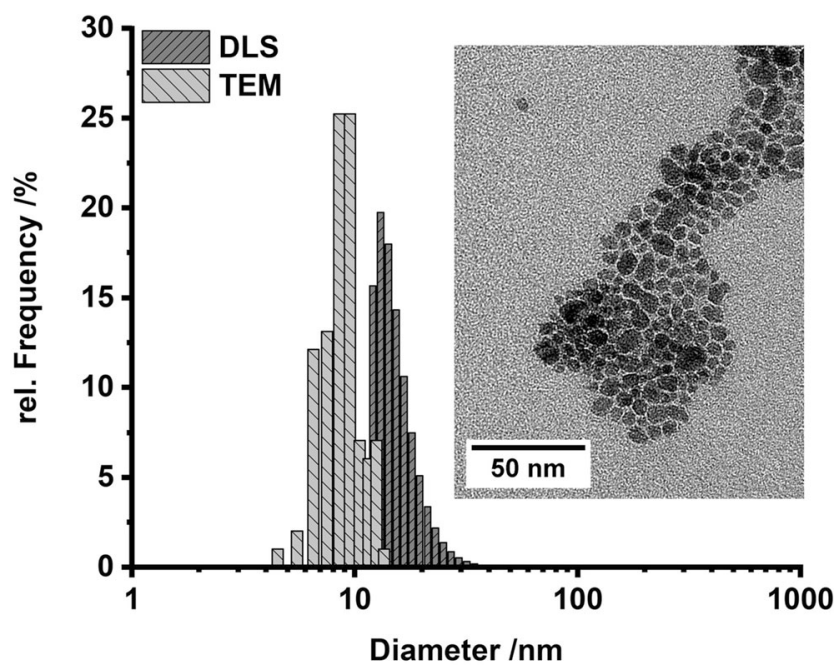

Fig. 2 Particle size distribution of $\gamma-\mathrm{Fe}_{2} \mathrm{O}_{3}$ nanoparticles as determined by DLS measurements (dark gray) and by TEM image analysis (light gray), Inset: TEM image of $\gamma-\mathrm{Fe}_{2} \mathrm{O}_{3}$ nanoparticles

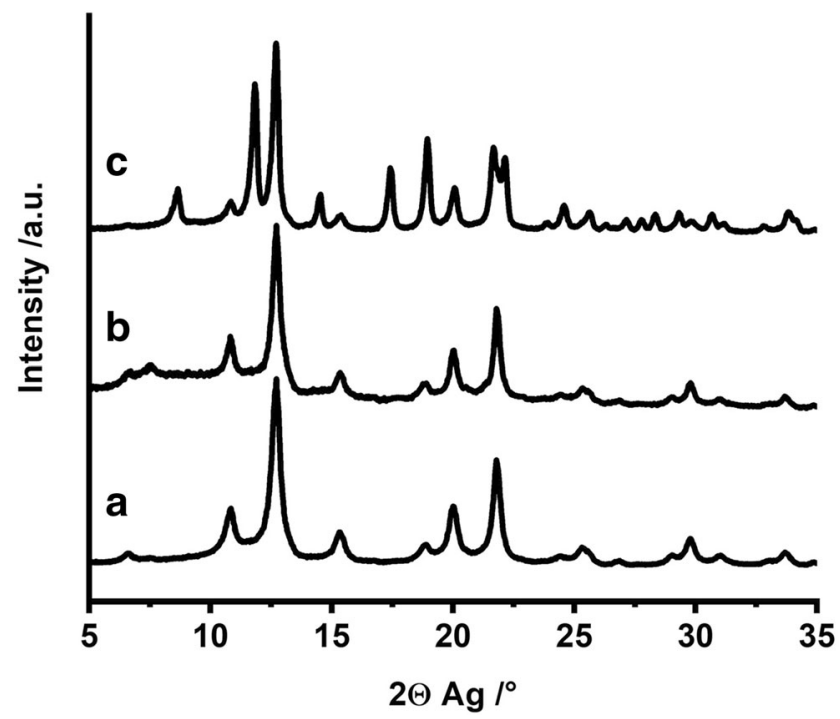

Fig. 3 PXRD pattern of (a) $\gamma-\mathrm{Fe}_{2} \mathrm{O}_{3}$ nanoparticles, (b) hybrid material, and (c) mesostructured $\mathrm{Fe}_{2} \mathrm{O}_{3}$ obtained by calcination

observed at $4.2 \mathrm{~K}$, but not fast enough to wipe out any magnetic hyperfine interactions, which would result in a quadrupole doublet with narrow lines.

\section{Formation of the cylindrical hybrid material}

The citrate-stabilized $\gamma-\mathrm{Fe}_{2} \mathrm{O}_{3}$ nanoparticles carry a negative surface potential at $\mathrm{pH} 6$ as confirmed by a zeta potential of $42 \mathrm{mV}$ (Fig. S5). This allowed for a robust hybrid formation via electrostatic interactions with the positively charged CPBs. After removing excess nanoparticles and drying the hybrid material, nanorods (Fig. 5a-d) with a high aspect ratio forming a non-woven microstructure were obtained. The rods were several micrometers in length with a diameter of $118 \pm$ $8 \mathrm{~nm}$ as evidenced by grayscale analysis (Fig. S6).

Neither the phase nor the crystallite size of $\gamma-\mathrm{Fe}_{2} \mathrm{O}_{3}$ is affected by mesostructuring as indicated by Mössbauer and PXRD measurements. Mössbauer spectra recorded at $4.2 \mathrm{~K}$ (Fig. 4b) still could be fitted with two sextet sub-spectra similar to the pure nanoparticles. There are no significant changes for isomeric shifts and hyperfine fields $\left(\mathrm{Fe}^{3+}\right.$ in tetrahedral sites: $\delta=0.04 \mathrm{~mm} \mathrm{~s}^{-1} ; \mathrm{Fe}^{3+}$ in octahedral sites: $\delta=$ $0.32 \mathrm{~mm} \mathrm{~s}^{-1}$ ) compared to the pure nanoparticles discussed above. In the room temperature spectrum (Fig. S4) a larger contribution of the broad pattern still a sextet shape is observed compared to the as-prepared nanoparticles. This indicates slower relaxation for the nanoparticles attached to the polymer, probably because of magnetic interactions between the adsorbed nanoparticles, which slows down the relaxation.

The amorphous CPBs do not contribute any reflex to the diffraction pattern (Fig. 3b). Coherently scattering domain sizes as obtained by Rietveld analysis (Fig. S8, Table S2) 


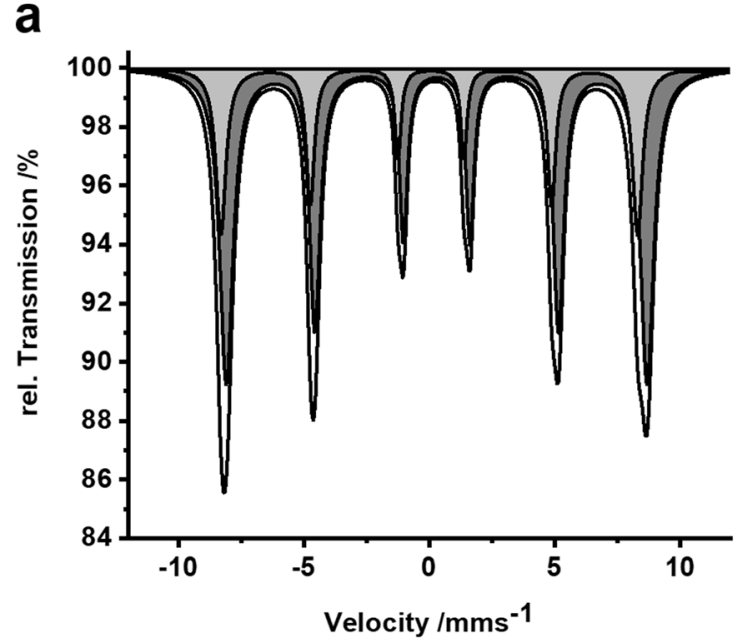

Fig. 4 a Mössbauer spectrum of the $\gamma-\mathrm{Fe}_{2} \mathrm{O}_{3}$ nanoparticles (black line) at $4.2 \mathrm{~K}$ with fitted sub-spectra (light gray: sextet with $\delta=0.05 \mathrm{~mm} \mathrm{~s}^{-1}$; dark gray: sextet with $\delta=0.29 \mathrm{~mm} \mathrm{~s}^{-1}$ ). b Mössbauer spectrum of the hybrid

increases only insignificantly to 5.01(4)-7.01(6) nm upon hybrid formation.

The specific surface area of the dried hybrid material as determined from nitrogen physisorption measurements via the Brunauer-Emmett-Teller method (BET) was $64 \mathrm{~m}^{2} \mathrm{~g}^{-1}$ (Fig. 6a). Thermogravimetric analysis results in an iron oxide to $\mathrm{CPB}$ ratio of $3: 1$.

\section{Pyrolysis to $\mathrm{Fe}_{2} \mathrm{O}_{3}$ nanotubes}

To remove the structure-directing $\mathrm{CPBs}$, the hybrid material was calcined in synthetic air at $500^{\circ} \mathrm{C}$. Rod-like morphology and high aspect ratio are maintained (Fig. 5e-h). Upon calcination, the hybrid material was converted into nanotubes as b

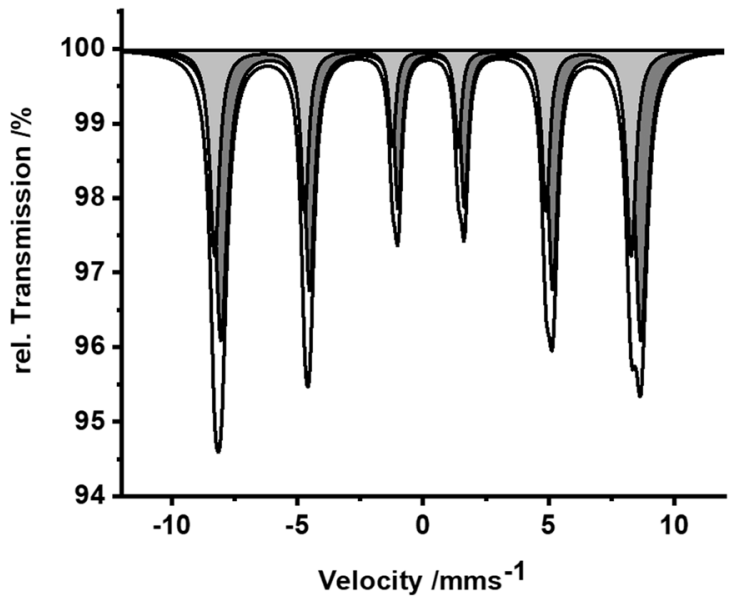

material (black line) at $4.2 \mathrm{~K}$ with fitted sub-spectra (light gray: sextet with $\delta=0.04 \mathrm{~mm} \mathrm{~s}^{-1}$; dark gray: sextet with $\delta=0.32 \mathrm{~mm} \mathrm{~s}^{-1}$ )

evidenced by grayscale analysis (Fig. S7). The BET-surface area decreases about $15 \%$ from 64 to $54 \mathrm{~m}^{2} \mathrm{~g}^{-1}$ due to Ostwald ripening and sintering of the nanoparticles (Fig. 6a). The pore size distribution calculated by the Barret-JoynerHalenda (BJH) model shows the presence of some mesopores totaling to a pore volume of $\approx 0.16 \mathrm{~cm}^{3} \mathrm{~g}^{-1}$. The $d_{50}$ pore diameter for the mesoporous region is $9.5 \mathrm{~nm}$ (Fig. 6a, inset).

Calcination triggers partial conversion of the metastable $\gamma$ $\mathrm{Fe}_{2} \mathrm{O}_{3}$ to $\alpha-\mathrm{Fe}_{2} \mathrm{O}_{3}$. The Mössbauer spectrum recorded at $4.2 \mathrm{~K}$ (Fig. 6b) could be fitted with a total of three sextet subspectra. Two sextets with isomeric shifts of $\delta=0.09 \mathrm{~mm} \mathrm{~s}^{-1}$ and $\delta=$ $0.30 \mathrm{~mm} \mathrm{~s}^{-1}$ with hyperfine fields of $52 \mathrm{~T}$ and low quadrupole shifts are assigned to $\mathrm{Fe}^{3+}$ atoms in the tetrahedral and octahedral positions of $\gamma-\mathrm{Fe}_{2} \mathrm{O}_{3}$. The remaining sextet with an
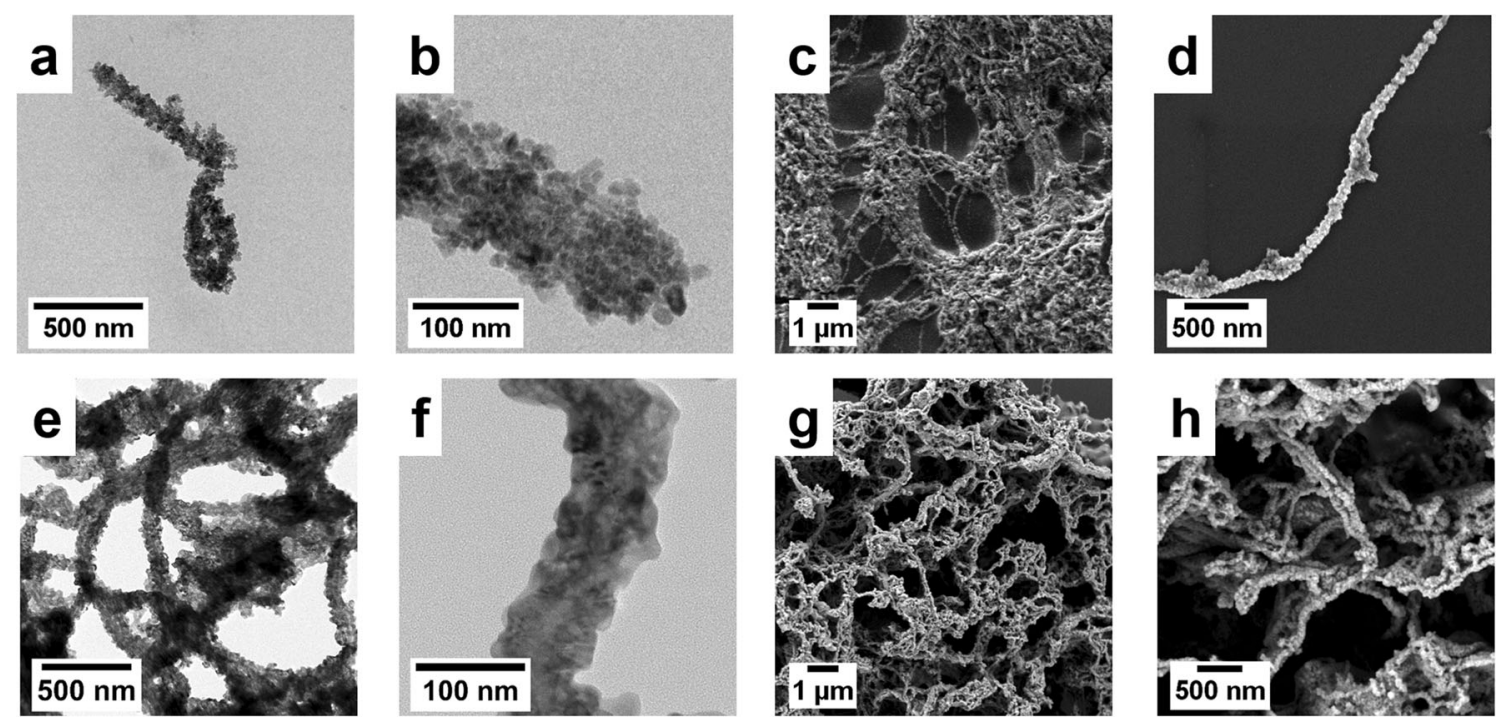

Fig. 5 TEM $(\mathbf{a}, \mathbf{b})$ and SEM micrographs $(\mathbf{c}, \mathbf{d})$ of the $\gamma-\mathrm{Fe}_{2} \mathrm{O}_{3}$ hybrid material; TEM $(\mathbf{e}, \mathbf{f})$ and SEM $(\mathbf{g}, \mathbf{h})$ micrographs of the mesostructured Fe $\mathrm{O}_{3}$ obtained after template removal 


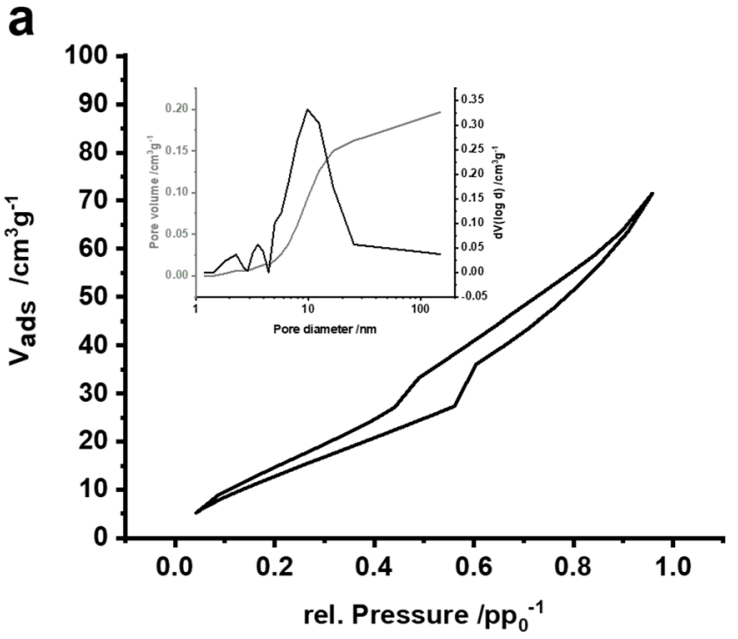

Fig. 6 a $\mathrm{N}_{2}$-sorption isotherms of the mesostructured $\mathrm{Fe}_{2} \mathrm{O}_{3}$ obtained after template removal. The pore size distribution integrated pore volume as calculated applying the $\mathrm{BJH}$ model is shown in the inset. b Mössbauer spectrum of the calcined $\mathrm{Fe}_{2} \mathrm{O}_{3}$ nanotubes recorded at $4.2 \mathrm{~K}$

isomeric shift of $\delta=0.23 \mathrm{~mm} \mathrm{~s}^{-1}$, a quadrupole shift of $\Delta=$ $0.30 \mathrm{~mm} \mathrm{~s}^{-1}$ and a hyperfine field of $54 \mathrm{~T}$ belongs to $\alpha-\mathrm{Fe}_{2} \mathrm{O}_{3}$. It implies that $\alpha-\mathrm{Fe}_{2} \mathrm{O}_{3}$ has undergone the Morin transition, after which a quadrupole shift of $\Delta=0.4 \mathrm{~mm} \mathrm{~s}^{-1}$ is expected for well-crystallized $\alpha-\mathrm{Fe}_{2} \mathrm{O}_{3}$. The lower quadrupole shift found in the calcined sample can be explained by an imperfect spin orientation along the crystallographic $c$-axis. The amount of hematite determined from the $4.2 \mathrm{~K}$ spectrum was $40 \%$, while $51 \%$ results from evaluation of the spectra at room temperature (Fig. S4). The presence of two different iron oxide phases is also confirmed by additional reflexes observed in the PXRD pattern (Fig. 3c). Quantitative Rietveld refinement (Fig. S9, Table S3) yielded coherently scattering domain sizes of 12.17(9)-17.01(11) nm for $\alpha-\mathrm{Fe}_{2} \mathrm{O}_{3}$ and 6.65(9)-9.30(12) $\mathrm{nm}$ for $\gamma-\mathrm{Fe}_{2} \mathrm{O}_{3}$, respectively.

The calcined $\mathrm{Fe}_{2} \mathrm{O}_{3}$ nanotubes showed a significant higher absorption in the visible range compared to Aeroxide ${ }^{\circledR} \mathrm{TiO}_{2}$ P25 (Fig. 7). Using the Tauc plot for diffuse reflection data, the bandgap of the material is calculated as $1.9 \mathrm{eV}$ for the $\mathrm{Fe}_{2} \mathrm{O}_{3}$ sample and $3.4 \mathrm{eV}$ for $\mathrm{TiO}_{2}$ (Fig. $\mathrm{S} 10$ ).

The point of zero charge (PZC) for the mesostructured calcined $\alpha / \gamma-\mathrm{Fe}_{2} \mathrm{O}_{3}$ nanotubes was found at $\mathrm{pH}=9.5$, as determined by $\mathrm{pH}$-dependent streaming potential measurements. This value is in good agreement with data for iron oxide made via synthesis routes comparable to what has been used here (Kosmulski 2016). Mott-Schottky analyses (Fig. S11) of the nanotubes resulted in a flat band potential of + $0.31 \mathrm{~V}_{\mathrm{RHE}}$. The positive slope indicates n-typical behavior. The determined flat band potential matches well with values found in the literature for $\alpha-\mathrm{Fe}_{2} \mathrm{O}_{3}$ and is therefore ascribed to the conduction band edge of the $\alpha-\mathrm{Fe}_{2} \mathrm{O}_{3}$ fraction (Gilbert et al. 2013; Sivula and van de Krol 2016).

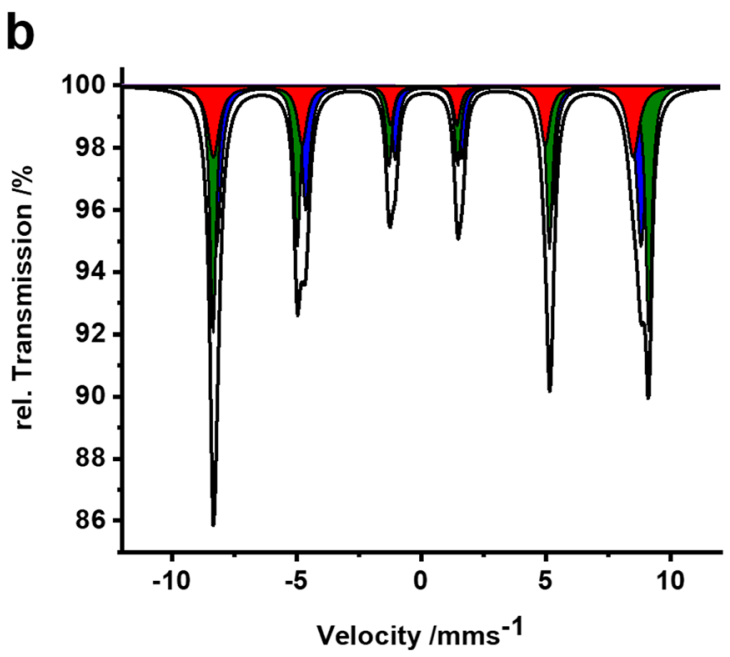

(black) with fitted sextet subspectra for maghemite (red: $\delta=0.09 \mathrm{~mm} \mathrm{~s}^{-1}$ for $\mathrm{Fe}^{3+}$ in tetrahedral sites; blue: $\delta=0.3 \mathrm{~mm} \mathrm{~s}^{-1}$ for $\mathrm{Fe}^{3+}$ in octahedral sites) and hematite (green: $\delta=0.23 \mathrm{~mm} \mathrm{~s}^{-1}$ )

\section{Photocatalytic degradation of ciprofloxacin}

The photocatalytic degradation was conducted in a selfconstructed continuous flow reactor (Fig. S1). The photocatalytic $\alpha / \gamma-\mathrm{Fe}_{2} \mathrm{O}_{3}$ nanotubes $(20 \mathrm{mg})$ were placed onto a glass microfiber filter ensuring a homogenous flow. After equilibration in the dark for $120 \mathrm{~min}$, the degradation of ciprofloxacin was monitored for $120 \mathrm{~min}$ at $\mathrm{pH}=8$ applying terrestrial solar radiation. The degradation kinetics were compared to a commercial $\mathrm{TiO}_{2}$ photocatalyst (Aeroxide ${ }^{\circledR} \mathrm{TiO}_{2}$ P25, $80 \%$ anatase and $20 \%$ rutile with a surface area of approximately $50 \mathrm{~m}^{2} \mathrm{~g}^{-1}$ ) and $\mathrm{ZnO}$ nanotubes studied in a previous work (Bojer et al. 2017). Under the applied

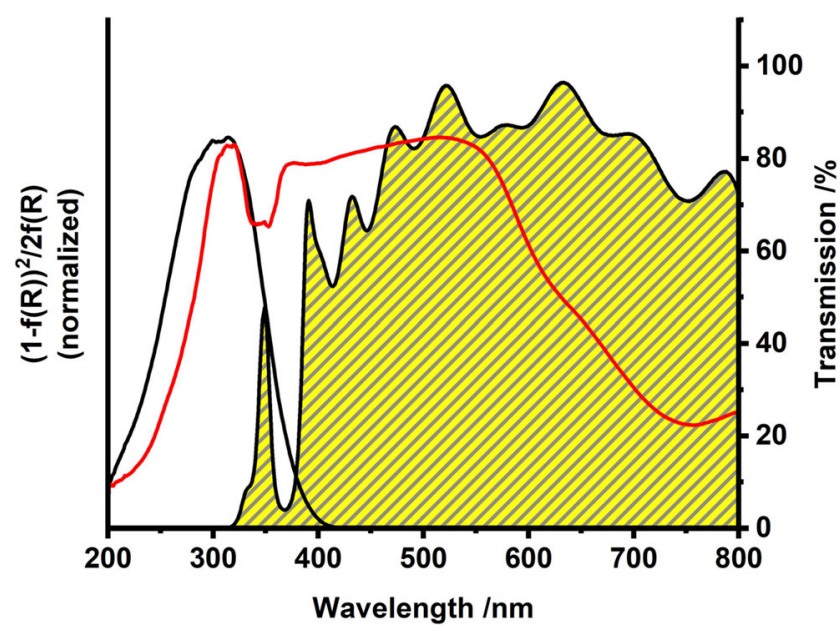

Fig. 7 Absorption spectra of Degussa P25 (black) and $\alpha / \gamma-\mathrm{Fe}_{2} \mathrm{O}_{3}$ nanotubes (red) obtained from diffuse reflection data. The yellow shaded curve represents the transmission spectrum of the AM1.5 filter used in the photocatalytic tests 
conditions, the synthesized $\alpha / \gamma-\mathrm{Fe}_{2} \mathrm{O}_{3}$ nanotubes are by far superior to both reference materials. After $120 \mathrm{~min}$, the $\alpha / \gamma-\mathrm{Fe}_{2} \mathrm{O}_{3}$ nanotubes removed $17 \%$ of ciprofloxacin whereas only $4.5 \%$ and $12 \%$ of the initial ciprofloxacin concentration was degraded when Aeroxide ${ }^{\circledR} \mathrm{TiO}_{2} \mathrm{P} 25$ or $\mathrm{ZnO}$ nanotubes were used (Fig. 8a). A blank measurement without photocatalyst showed that irradiation alone lead to only insignificant degradation of ciprofloxacin $(\approx 1 \%)$.

Assuming pseudo-first-order kinetics (Gaya and Abdullah 2008), the apparent rate constants $k^{\prime}$ were determined from the slope of the linear fit in the $\ln \left(c_{0} / c_{t}\right) v$ s. $t$ plot (Fig. 8a). With a rate constant of $k^{\prime}=1.51 \times 10^{-3} \mathrm{~min}^{-1}$, the $\alpha / \gamma-\mathrm{Fe}_{2} \mathrm{O}_{3}$ nanotubes are 4.5 times faster in photodegrading ciprofloxacin as compared to Aeroxide ${ }^{\circledR} \mathrm{TiO}_{2} \mathrm{P} 25\left(k^{\prime}=3.4 \times 10^{-4} \mathrm{~min}^{-1}\right)$ and 1.6 times faster than $\mathrm{ZnO}$ nanotubes $\left(k^{\prime}=9.61 \times 10^{-4} \mathrm{~min}^{-1}\right)$, respectively.

What are possible reasons for the superior performance of the $\mathrm{Fe}_{2} \mathrm{O}_{3}$ nanotubes?

At slightly basic conditions of $\mathrm{pH}=8$, which are typically encountered with clinical wastewater (Gartiser et al. 1996), ciprofloxacin is present in its anionic form (IEP at $\mathrm{pH}=7.4$ (Torniainen et al. 1996)). At the same time, $\alpha / \gamma-\mathrm{Fe}_{2} \mathrm{O}_{3}$ nanotubes with a $\mathrm{PZC}$ at $\mathrm{pH}=9.5$ carry an oppositely charged positive surface charge. Under these boundary conditions set by the application, adsorption is highly favored because it is driven by Coulomb attraction.

Contrary to $\alpha / \gamma-\mathrm{Fe}_{2} \mathrm{O}_{3}$ nanotubes, the surface of $\mathrm{TiO}_{2}$ is negatively charged at basic $\mathrm{pH}$ values, and consequently, the adsorption of anionic ciprofloxacin is electrostatically disfavored. Both $\mathrm{ZnO}$ nanotubes as well as $\alpha / \gamma-\mathrm{Fe}_{2} \mathrm{O}_{3}$ nanotubes carry a positive surface charge at the $\mathrm{pH}$ of clinical wastewater and consequently are superior in the photodegradation of ciprofloxacin over Aeroxide ${ }^{\circledR} \mathrm{TiO}_{2} \mathrm{P} 25$.

Both $\mathrm{ZnO}$ and $\mathrm{TiO}_{2}$, however, have large bandgaps only allowing for absorption of the small UV fraction of the terrestrial solar spectrum. Contrary to these previously studied photocatalysts, the bandgap of $\mathrm{Fe}_{2} \mathrm{O}_{3}$ nanotubes $(1.9 \mathrm{eV})$ leads to an absorption close to the maximum of the solar radiation and a much larger fraction of light can be utilized for photoexcitation and charge carrier generation (Fig. 7). While allowing for filtration, the mesoporous non-woven structure at the same time provides good accessibility to a high specific surface area $\left(54 \mathrm{~m}^{2} \mathrm{~g}^{-1}\right.$, Fig. 6) and ensures a high mass transfer through the catalyst material. Together with shortened diffusion pathways for charge carriers by small crystallite sizes, the overall photocatalytic efficiency is significantly improved compared to commercial available hematite powder (microcrystalline; $3.4 \%$ degradation within $120 \mathrm{~min}$ and $k^{\prime}=2.9 \times 10^{-4} \mathrm{~min}^{-1}$, Fig. 8). At this point, it is rather unclear if a heterojunction due to slightly varying band positions between the two iron oxide polymorphs within the nanotubes is formed. Heterojunction formation would contribute favorably to charge carrier separation and therefore would be expected to improve photocatalytic activity of the $\alpha / \gamma-\mathrm{Fe}_{2} \mathrm{O}_{3}$ nanotubes as compared to the reference materials (Liu 2012; Aslam et al. 2018).

The concentration of ciprofloxacin at the surface of the photocatalyst facilitates degradation either by direct reaction with surface trapped charge carriers or intermediate radical species. Comparing the absolute positions of the valence band of $\mathrm{Fe}_{2} \mathrm{O}_{3}$ nanotubes $(-6.9 \mathrm{eV}$; obtained and converted from diffuse reflection and Mott-Schottky data) with the HOMO level of ciprofloxacin (- $5.72 \mathrm{eV}$ (Stefaniu and Pintilie 2018)), an oxidative degradation is the most likely mechanism (Fig. 9).

Pan et al. (2018) and Mesa et al. (2017) have suggested that methanol and isopropyl alcohol are photooxidized by iron oxide. In this line and consistent with an oxidative mechanism, when adding methanol and isopropyl alcohol as competing hole scavengers, indeed the degradation of ciprofloxacin was diminished to $7 \%\left(k^{\prime}=6.1 \times 10^{-4} \mathrm{~min}^{-1}\right)$ and $5 \%\left(k^{\prime}=4.1 \times\right.$ $\left.10^{-4} \mathrm{~min}^{-1}\right)$, respectively. Despite the high concentration of

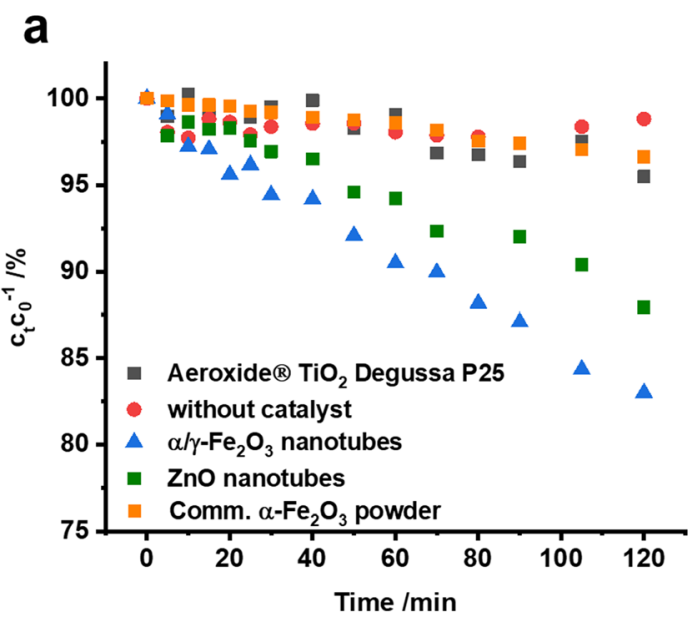

b

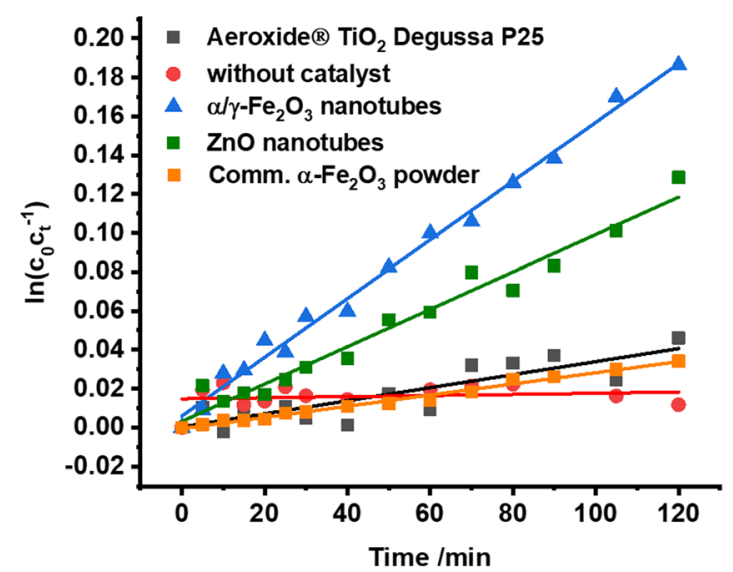

Fig. 8 Time-dependent degradation of ciprofloxacin during irradiation with solar spectrum (a) and corresponding pseudo-first-order kinetic plots (b) 
Fig. 9 Comparison of the absolute positions of the valence and conduction band of $\mathrm{Fe}_{2} \mathrm{O}_{3}$ nanotubes with $\mathrm{HOMO}$ and LUMO levels of ciprofloxacin

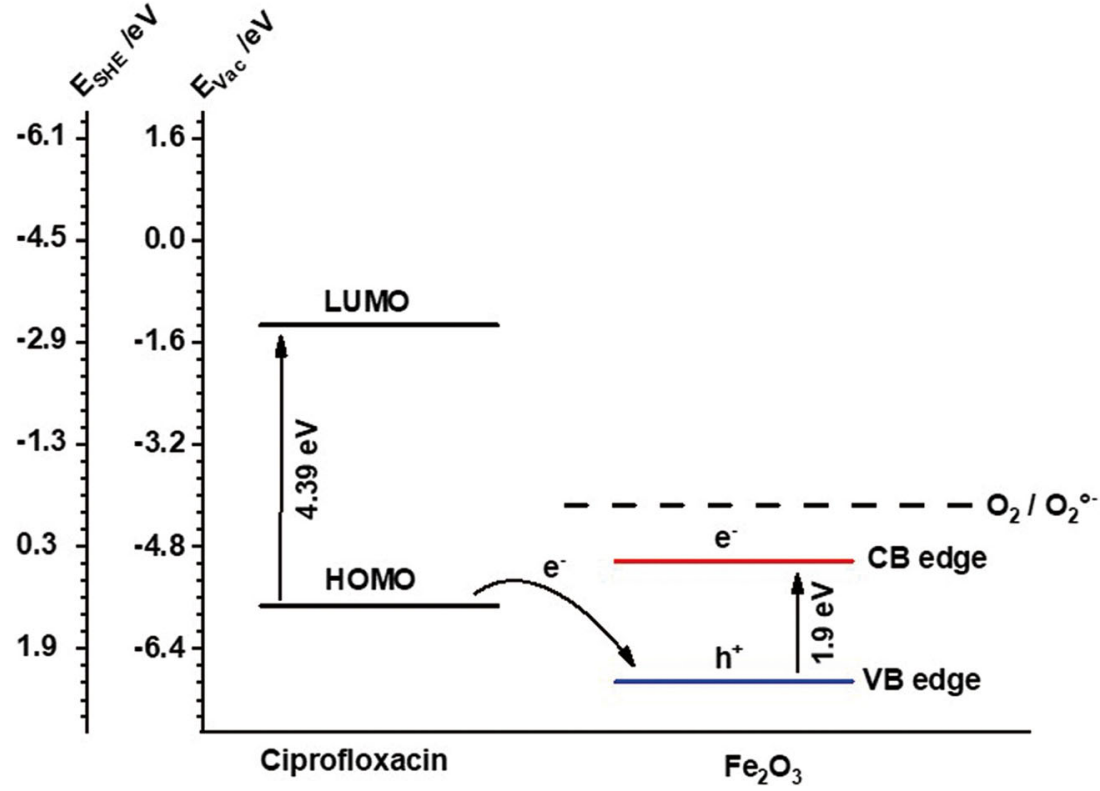

scavenger applied as compared to the ciprofloxacin concentration, the degradation, however, cannot be suppressed completely. Apparently, the electrostatic interactions between the positively charged photocatalyst surface and anionic ciprofloxacin makes ciprofloxacin competitive with neutral scavengers despite the large difference in concentration. The competitive experiments thus suggest direct oxidation of ciprofloxacin by surface trapped holes to be the dominant degradation mechanism.

The fate of the photoexcited electron in the conduction band and the mechanism for regeneration of the transient reduced $\alpha / \gamma-\mathrm{Fe}_{2} \mathrm{O}_{3}$ are less obvious. Judging on the published positions of the $\mathrm{O}_{2} / \mathrm{O}_{2}{ }^{-}$redox potential $(-4.2 \mathrm{eV})$, reduction of oxygen by electrons in the conduction band of $\mathrm{Fe}_{2} \mathrm{O}_{3}$ nanotubes $(-5.0 \mathrm{eV})$ should actually be thermodynamically forbidden (Wood 1974). Despite this, applying a method introduced by the group of Ide (Mani et al. 2018), the formation of superoxide radicals could nevertheless be confirmed experimentally. Ide et al. (Mani et al. 2018) showed that the presence of superoxide radicals $\left(\mathrm{O}_{2}^{-{ }^{-}}\right)$can be proven experimentally by the formation of water-insoluble blue formazans on the catalysts surface via reaction of $\mathrm{O}_{2}{ }^{-\cdot}$ with nitro blue tetrazolium (NBT).

$\alpha / \gamma-\mathrm{Fe}_{2} \mathrm{O}_{3}$ nanotubes were found to photodegrade $15 \%$ of dissolved NBT within an hour when illuminated with terrestrial solar spectrum while blue formazans formed on the surface (Fig. 10). Without light or catalyst, no significant degradation could be observed. A possible explanation for the apparent contradiction might be the recently proposed model by Jaegermann (Lohaus et al. 2018), indicating that the electrochemically measured conduction band minima of iron oxides are most probably polaron trap levels, and the actual
Fig. 10 Concentration of nitro blue tetrazolium in the presence of catalyst with (green circles) and without irradiation (black circles) as well as under illumination without catalyst (red circles). Photocatalytic performance of $\alpha / \gamma-\mathrm{Fe}_{2} \mathrm{O}_{3}$ nanotubes in the degradation of ciprofloxacin in an Ar atmosphere (blue triangles). The pictures on the right side show the photocatalysts color before NBT reduction (top) and the color change due to deposition of water-insoluble formazans (Mani et al. 2018) on the catalyst surface (bottom)

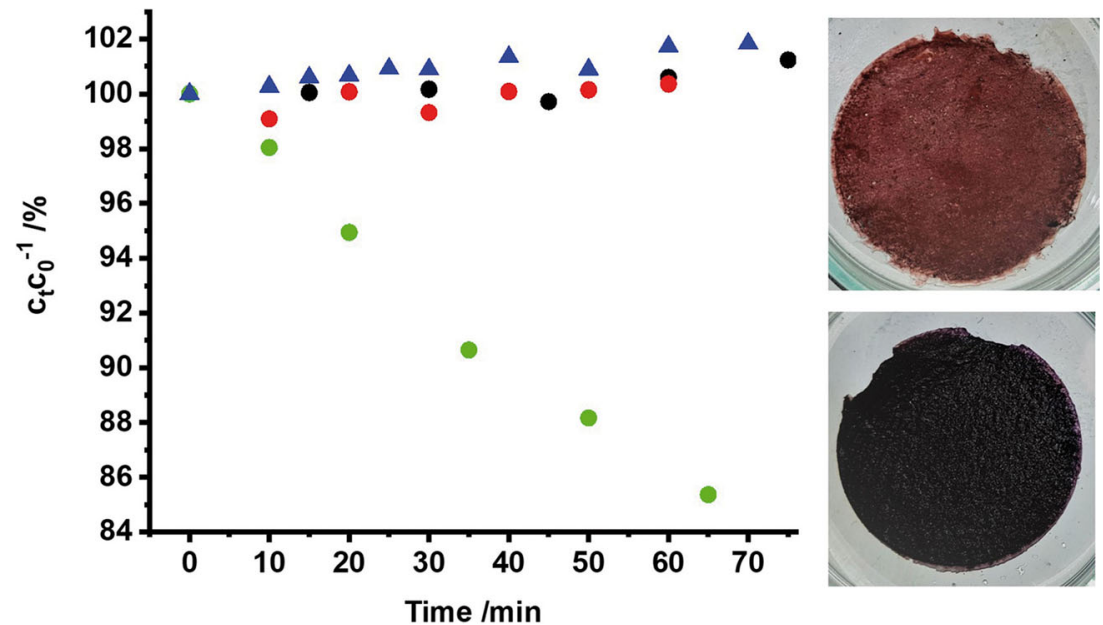


conduction band minimum lies much more cathodic, being able to reduce oxygen. Although photoexcited electrons are usually trapped very fast in those polaron trap states, some might still be able to reduce $\mathrm{O}_{2}$ during the oxidative degradation of ciprofloxacin.

In summary, our experiments suggest the degradation of ciprofloxacin to involve direct oxidation via holes with parallel reduction of oxygen to form superoxide radicals (Fig. 10). In line with this view, the photodegradation in Ar-saturated solution is significantly less efficient (Fig. 10). Moreover, the superoxide radical intermediate is expected to contribute to the degradation, for instance via disproportionation to $\mathrm{H}_{2} \mathrm{O}_{2}$ (Chong et al. 2010).

Most importantly, the mesostructured catalyst cannot only be applied in a flow-through cell but can also be easily recovered from the fluid reaction medium by filtration. There is no need for expensive techniques like ultracentrifugation.

\section{Conclusion}

Mesostructured $\mathrm{Fe}_{2} \mathrm{O}_{3}$ allows for an efficient photodegradation of ciprofloxacin at the basic $\mathrm{pH}$ of clinical wastewaters. Moreover, due to an adsorption band close to the maximum of the solar spectrum, this photocatalyst is superior to the large bandgap semiconductors $\mathrm{P} 25$ or $\mathrm{ZnO}$. The smaller bandgap allows to utilize a larger fraction of the solar radiation for charge carrier generation. In addition, the non-woven-like mesostructure minimizes diffusion pathways to the surface while at the same time ensuring a high mass transport through the catalyst as well as simple recycling by filtration.

Scavenger experiments suggest direct oxidation of ciprofloxacin via holes and a reduction of dissolved oxygen gas to form superoxide radicals. Simple $\mathrm{O}_{2}$ is thus fully sufficient in this advanced photooxidation process with no need to add expensive $\mathrm{H}_{2} \mathrm{O}_{2}$ triggering a Fenton-type reaction.

Acknowledgments The authors thank Professor M. Zobel (University of Bayreuth) for access to the STOE Stadi P. We appreciate the support of the Keylab for Optical and Electron Microscopy of the Bavarian Polymer Institute (BPI), and we thank Marco Schwarzmann for taking TEM images.

Author contributions All authors (DRW, KA, LM, TM, AB, HS, RM, FEW, JB) made substantial contribution to the conception and design of the work, acquisition, analysis, and interpretation of data. DWR and KA prepared the photocatalyst and conducted the degradation studies. LM, $\mathrm{TM}, \mathrm{AB}, \mathrm{HS}, \mathrm{RM}$, and FEW contributed in performing analytic measurements and helped with the interpretation of the data. DW and JB wrote the manuscript. All authors have been involved in drafting or revising the manuscript critically for important intellectual content. All authors have given final approval of the version to be published.

Funding Open Access funding enabled and organized by Projekt DEAL. This work was funded by the Collaborative Research Center (SFB) 840.

\section{Compliance with ethical standards}

Ethical approval Not applicable.

Consent to participate Not applicable.

Consent to publish Not applicable.

Competing interests The authors declare that they have no competing interests.

Availability of data Datasets used and/or analyzed are available from the corresponding author on reasonable request.

Open Access This article is licensed under a Creative Commons Attribution 4.0 International License, which permits use, sharing, adaptation, distribution and reproduction in any medium or format, as long as you give appropriate credit to the original author(s) and the source, provide a link to the Creative Commons licence, and indicate if changes were made. The images or other third party material in this article are included in the article's Creative Commons licence, unless indicated otherwise in a credit line to the material. If material is not included in the article's Creative Commons licence and your intended use is not permitted by statutory regulation or exceeds the permitted use, you will need to obtain permission directly from the copyright holder. To view a copy of this licence, visit http://creativecommons.org/licenses/by/4.0/.

\section{References}

Aslam M, Qamar MT, Rehman AU, Soomro MT, Ali S, Ismail IMI, Hameed A (2018) The evaluation of the photocatalytic activity of magnetic and non-magnetic polymorphs of $\mathrm{Fe} 2 \mathrm{O} 3$ in natural sunlight exposure: a comparison of photocatalytic activity. Appl Surf Sci 451:128-140. https://doi.org/10.1016/j.apsusc.2018.04.219

Boillot C, Bazin C, Tissot-Guerraz F, Droguet J, Perraud M, Cetre JC, Trepo D, Perrodin Y (2008) Daily physicochemical, microbiological and ecotoxicological fluctuations of a hospital effluent according to technical and care activities. Sci Total Environ 403:113-129. https://doi.org/10.1016/j.scitotenv.2008.04.037

Bojer C, Schöbel J, Martin T, Ertl M, Schmalz H, Breu J (2017) Clinical wastewater treatment: photochemical removal of an anionic antibiotic (ciprofloxacin) by mesostructured high aspect ratio $\mathrm{ZnO}$ nanotubes. Appl Catal B Environ 204:561-565. https://doi.org/10.1016/ j.apcatb.2016.12.003

Bound JP, Voulvoulis N (2005) Household disposal of pharmaceuticals as a pathway for aquatic contamination in the United Kingdom. Environ Health Perspect 113:1705-1711. https://doi.org/10.1289/ ehp. 8315

Brown KD, Kulis J, Thomson B, Chapman TH, Mawhinney DB (2006) Occurrence of antibiotics in hospital, residential, and dairy effluent, municipal wastewater, and the Rio Grande in New Mexico. Sci Total Environ 366:772-783. https://doi.org/10.1016/j.scitotenv. 2005.10.007

Chong MN, Jin B, Chow CWK, Saint C (2010) Recent developments in photocatalytic water treatment technology: A review. Water Res 44: 2997-3027. https://doi.org/10.1016/j.watres.2010.02.039

Clara-Rahola J, Fernandez-Nieves A, Sierra-Martin B, South AB, Lyon LA, Kohlbrecher J, Fernandez Barbero A (2012) Structural properties of thermoresponsive poly(N-isopropylacrylamide)poly(ethyleneglycol) microgels. J Chem Phys 136:214903. https:// doi.org/10.1063/1.4723686 
Costa TMS, Lima MS, Filho JFC et al (2018) Synthesis, characterization, and photocatalytic activity of Ag3PO4/SBA-15 in ciprofloxacin degradation under polychromatic irradiation. J Photochem Photobiol A Chem 364:461-471. https://doi.org/10.1016/j. jphotochem.2018.06.039

Gartiser S, Brinker L, Erbe T, Kümmerer K, Willmund R (1996) Belastung von Krankenhausabwasser mit gefährlichen Stoffen im Sinne § 7a WHG. Acta Hydrochim Hydrobiol 24:90-97. https://doi. org/10.1002/aheh.19960240206

Gaya UI, Abdullah AH (2008) Heterogeneous photocatalytic degradation of organic contaminants over titanium dioxide: a review of fundamentals, progress and problems. J Photochem Photobiol C Photochem Rev 9:1-12. https://doi.org/10.1016/j.jphotochemrev. 2007.12.003

Gilbert B, Katz JE, Huse N, Zhang X, Frandsen C, Falcone RW, Waychunas GA (2013) Ultrafast electron and energy transfer in dye-sensitized iron oxide and oxyhydroxide nanoparticles. Phys Chem Chem Phys 15:17303-17313. https://doi.org/10.1039/ c3cp53368a

Guo T, Wang K, Zhang G, Wu X (2019) A novel $\alpha$-Fe2O3@g-C3N4 catalyst: synthesis derived from Fe-based MOF and its superior photo-Fenton performance. Appl Surf Sci 469:331-339. https:// doi.org/10.1016/j.apsusc.2018.10.183

Hartmann A, Alder AC, Koller T, Widmer RM (1998) Identification of flouroquinolone antibiotics as the main soure of umuC genotoxicity in native hospital wastewater. Environ Toxicol Chem 17:377-382. https://doi.org/10.1002/etc.5620170305

Jiang JQ, Zhou Z, Sharma VK (2013) Occurrence, transportation, monitoring and treatment of emerging micro-pollutants in waste water - a review from global views. Microchem J 110:292-300. https://doi. org/10.1016/j.microc.2013.04.014

Khan MM, Adil SF, Al-Mayouf A (2015) Metal oxides as photocatalysts. J Saudi Chem Soc 19:462-464. https://doi.org/10.1016/j.jscs.2015. 04.003

Khedr MH, Abdel Halim KS, Soliman NK (2009) Synthesis and photocatalytic activity of nano-sized iron oxides. Mater Lett 63:598-601. https://doi.org/10.1016/j.matlet.2008.11.050

Kosmulski M (2016) Isoelectric points and points of zero charge of metal (hydr)oxides: 50 years after Parks' review. Adv Colloid Interface Sci 238:1-61. https://doi.org/10.1016/j.cis.2016.10.005

Lindberg R, Jarnheimer PÅ, Olsen B, Johansson M, Tysklind M (2004) Determination of antibiotic substances in hospital sewage water using solid phase extraction and liquid chromatography/mass spectrometry and group analogue internal standards. Chemosphere 57: 1479-1488. https://doi.org/10.1016/j.chemosphere.2004.09.015

Litter MI, Blesa MA (1988) Photodissolution of iron oxides. J Colloid Interface Sci 125:679-687. https://doi.org/10.1016/0021-9797(88) 90035-5

Liu S-Q (2012) Magnetic semiconductor nano-photocatalysts for the degradation of organic pollutants. Environ Chem Lett 10:209-216. https://doi.org/10.1007/s10311-011-0348-9

Lohaus C, Klein A, Jaegermann W (2018) Limitation of Fermi level shifts by polaron defect states in hematite photoelectrodes. Nat Commun 9:4309. https://doi.org/10.1038/s41467-018-06838-2

Loos R, Carvalho R, António DC, Comero S, Locoro G, Tavazzi S, Paracchini B, Ghiani M, Lettieri T, Blaha L, Jarosova B, Voorspoels S, Servaes K, Haglund P, Fick J, Lindberg RH, Schwesig D, Gawlik BM (2013) EU-wide monitoring survey on emerging polar organic contaminants in wastewater treatment plant effluents. Water Res 47:6475-6487. https://doi.org/10.1016/j. watres.2013.08.024

Maji SK, Mukherjee N, Mondal A, Adhikary B (2012) Synthesis, characterization and photocatalytic activity of $\alpha-\mathrm{Fe} 2 \mathrm{O} 3$ nanoparticles. Polyhedron 33:145-149. https://doi.org/10.1016/j.poly.2011.11. 017
Mani D, Tsunoji N, Yumauchi Y, Arivanandhan M, Jayavel R, Ide Y (2018) Templated synthesis of atomically thin hematite platy nanoparticles within a layered silicate exhibiting efficient photocatalytic activity. J Mater Chem A 6:5166-5171. https://doi.org/10.1039/ C7TA10427H

Martins AF, Vasconcelos TG, Henriques DM, Frank CS, König A, Kümmerer K (2008) Concentration of ciprofloxacin in Brazilian hospital effluent and preliminary risk assessment: a case study. CLEAN - Soil, Air, Water 36:264-269. https://doi.org/10.1002/ clen.200700171

Mesa CA, Kafizas A, Francàs L, Pendlebury SR, Pastor E, Ma Y, le Formal F, Mayer MT, Grätzel M, Durrant JR (2017) Kinetics of photoelectrochemical oxidation of methanol on hematite photoanodes. J Am Chem Soc 139:11537-11543. https://doi.org/ $10.1021 /$ jacs. $7 \mathrm{~b} 05184$

Müllner M, Lunkenbein T, Miyajima N, Breu J, Müller AHE (2012) A facile polymer templating route toward high-aspect-ratio crystalline titania nanostructures. Small 8:2636-2640. https://doi.org/10.1002/ smll.201200738

Pal A, Gin KYH, Lin AYC, Reinhard M (2010) Impacts of emerging organic contaminants on freshwater resources: review of recent occurrences, sources, fate and effects. Sci Total Environ 408:60626069. https://doi.org/10.1016/j.scitotenv.2010.09.026

Pan H, Martindale KR, Heagy MD (2018) Iron oxide nanostructures for the reduction of bicarbonate to solar fuels. Top Catal 61:601-609. https://doi.org/10.1007/s11244-018-0959-5

Paul T, Dodd MC, Strathmann TJ (2010) Photolytic and photocatalytic decomposition of aqueous ciprofloxacin: transformation products and residual antibacterial activity. Water Res 44:3121-3132. https://doi.org/10.1016/j.watres.2010.03.002

Polyanskiy M (2019) Refractive Index Database. https://refractiveindex info/. Accessed 25 Aug 2019

Sivula K, van de Krol R (2016) Semiconducting materials for photoelectrochemical energy conversion. Nat Rev Mater 16010: 16010. https://doi.org/10.1038/natrevmats.2016.10

Stefaniu A, Pintilie L (2018) Molecular descriptors and properties of organic molecules. In: Akitsu T (ed) Symmetry (group theory) and mathematical treatment in chemistry. InTech, Rijeka, pp 161-176

Thomae SLJ, Prinz N, Hartmann T, Teck M, Correll S, Zobel M (2019) Pushing data quality for laboratory pair distribution function experiments. Rev Sci Instrum 90:043905. https://doi.org/10.1063/1. 5093714

Torniainen K, Tammilehto S, Ulvi V (1996) The effect of $\mathrm{pH}$, buffer type and drug concentration on the photodegradation of ciprofloxacin. Int J Pharm 132:53-61. https://doi.org/10.1016/0378-5173(95)04332-2

Van Doorslaer X, Demeestere K, Heynderickx PM et al (2011) UV-A and UV-C induced photolytic and photocatalytic degradation of aqueous ciprofloxacin and moxifloxacin: Reaction kinetics and role of adsorption. Appl Catal B Environ 101:540-547. https://doi.org/ 10.1016/j.apcatb.2010.10.027

Wood PM (1974) The redox potential of the system oxygen-superoxide. FEBS Lett 44:22-24. https://doi.org/10.1016/0014-5793(74)80297-8

Wu W, Jiang C, Roy VAL (2015) Recent progress in magnetic iron oxide-semiconductor composite nanomaterials as promising photocatalysts. Nanoscale 7:38-58. https://doi.org/10.1039/ c4nr04244a

Yelamanchili RS, Lu Y, Lunkenbein T, Miyajima N, Yan LT, Ballauff M, Breu J (2009) Shaping colloidal rutile into thermally stable and porous mesoscopic titania balls. Small 5:1326-1333. https://doi.org/ $10.1002 / \mathrm{smll} .200801298$

Publisher's note Springer Nature remains neutral with regard to jurisdictional claims in published maps and institutional affiliations. 